\title{
Neurodevelopmental outcome after early repair of a ventricular septal defect with or without aortic arch obstruction
}

Jonathan R. Kaltman, MD, ${ }^{\text {a }}$ Gail P. Jarvik, MD, PhD, ${ }^{\text {b } J u d y ~ B e r n b a u m, ~ M D, ~}{ }^{c}$ Gil Wernovsky, MD, ${ }^{\text {a }}$ Marsha Gerdes, $\mathrm{PhD},{ }^{d}$ Elaine Zackai, MD, ${ }^{\text {e }}$ Robert R. Clancy, MD, ${ }^{\dagger}$ Susan C. Nicolson, MD, ${ }^{g}$ Thomas L. Spray, MD, ${ }^{\mathrm{h}}$

and J. William Gaynor, MD ${ }^{\mathrm{h}}$

From the Divisions of Cardiology, ${ }^{\text {a }}$ General Pediatrics, ${ }^{\mathrm{c}}$ Psychology, ${ }^{\mathrm{d}}$ Genetics, ${ }^{\mathrm{e}}$ Neurology, ${ }^{\mathrm{f}}$ Cardiothoracic Anesthesia, ${ }^{\mathrm{g}}$ and Cardiothoracic Surgery, ${ }^{\text {h }}$ The Children's Hospital of Philadelphia, ${ }^{a}$ Philadelphia, Pa, and the Department of Medicine (Medical Genetics), the University of Washington, ${ }^{\mathrm{b}}$ Seattle, Wash.

Supported by an American Heart Association National Grant-In-Aid (9950480N), the Pew Biomedical Scholar Program, and the Fannie E. Rippel Foundation. Dr Kaltman was supported by a National Institutes of Health Training Grant (T32-HL07915).

Received for publication Oct 10, 2005; revisions received Dec 6, 2005; accepted for publication Dec 12, 2005.

Address for reprints: Jonathan Kaltman, MD, Division of Cardiology, The Children's Hospital of Philadelphia, 34th and Civic Center Blvd, Philadelphia, PA 19104 (E-mail: kaltman@email.chop.edu).

J Thorac Cardiovasc Surg 2006;131:792-8

$0022-5223 / \$ 32.00$

Copyright (๑) 2006 by The American Association for Thoracic Surgery

doi:10.1016/j.jtcvs.2005.12.023
Objectives: Cross-sectional studies of intermediate-term survivors of infant cardiac surgery have revealed a high frequency of neurodevelopmental disabilities. Few data exist regarding neurodevelopmental outcome of infants undergoing surgical intervention for a ventricular septal defect. The purpose of this study was to evaluate the neurodevelopmental outcome at 1 year of age of children who had surgical repair in infancy of a ventricular septal defect or a ventricular septal defect with aortic arch obstruction.

Methods: Children who underwent repair of a ventricular septal defect or singlestage repair of a ventricular septal defect with aortic arch obstruction at less than 6 months of age were assessed at 1 year of age by using the Bayley Scales of Infant Development II, which yields the Mental Development Index and the Psychomotor Development Index, both with an expected mean of $100 \pm 15$.

Results: At 1 year, 55 patients (ventricular septal defect alone $=36$; ventricular septal defect with aortic arch obstruction $=19$ ) returned for evaluation. The mean Mental Development Index was $92.6 \pm 11.7$, with $3(5 \%)$ patients scoring 70 or less. The mean Psychomotor Development Index was $86.1 \pm 16.4$, with $10(18 \%)$ patients scoring 70 or less. Patients with a suspected or confirmed genetic syndrome had both a lower Mental Development Index score $(P=.011)$ and a lower Psychomotor Development Index score $(P=.001)$. Mental Development Index and Psychomotor Development Index were independent of anatomic (specifically aortic arch obstruction) and intraoperative factors (specifically deep hypothermic circulatory arrest).

Conclusions: Neurodevelopmental outcome at 1 year of age was within the normal limits for most patients who underwent repair of a ventricular septal defect or a ventricular septal defect with aortic arch obstruction during infancy.

$\mathrm{V}$ entricular septal defects (VSDs) are one of the most common forms of congenital heart disease. Surgical intervention has long been the standard of care for hemodynamically significant lesions. Over the past 2 decades, improvements in surgical techniques and intensive care management have reduced postoperative mortality after VSD repair to minimal levels. ${ }^{1}$ Despite this history of success, little is known about the morbidity experienced by these children. Recent cross-sectional studies of intermediate-term survivors of infant cardiac surgery have revealed a high frequency of neurodevelopmental disabilities. ${ }^{2-4}$ However, no studies have specifically evaluated neurodevelopmental outcome of children who have undergone infant surgery for a VSD or a VSD with aortic arch obstruction. It is important to evaluate predictors of outcome so that support resources can be targeted to those at highest risk of neurodevelopmental disability. 


\section{Abbreviations and Acronyms \\ DHCA $=$ deep hypothermic circulatory arrest \\ $\mathrm{d}$-TGA $=\mathrm{d}$-transposition of the great arteries \\ MDI = Mental Development Index \\ PDI $=$ Psychomotor Development Index \\ VSD $=$ ventricular septal defect}

Important obstruction to systemic blood flow, either coarctation of the aorta or interruption of the aortic arch, coexists in a minority of patients with a VSD. However, arch obstruction carries significant implications for the child with a VSD because early circulatory collapse can occur in postnatally diagnosed patients in whom the ductus arteriosus closes, prostaglandin and other intensive care support might be necessary, and surgical intervention is required in the newborn period, rather than semielectively in later infancy. There remains some controversy regarding the optimal surgical approach, with some centers recommending simultaneous repair of the arch obstruction and VSD, whereas others recommend a lateral thoracotomy to repair the arch (with or without a pulmonary artery band), with closure of the VSD later in infancy. Although surgical mortality after single-stage repair has been shown to be acceptable, ${ }^{5}$ no study has evaluated neurodevelopmental outcome after single-stage repair, and there is little in the literature reporting the neurodevelopmental outcome of children with isolated VSDs.

The purpose of this study was to describe the neurodevelopmental outcome at 1 year of age in children who had surgical repair of a VSD or single-stage repair of a VSD with aortic arch obstruction during infancy and to identify potential determinants of this outcome.

\section{Methods}

This study constitutes a post-hoc analysis of a prospective trial assessing the effects of genetic polymorphisms on neurodevelopmental disabilities. ${ }^{6}$ The local institutional review board approved the study. Informed consent was obtained from the parents or legal guardians.

\section{Patient Population}

Patients less than 6 months of age who were undergoing cardiopulmonary bypass for repair of a VSD or a VSD with aortic arch obstruction (coarctation or interrupted aortic arch) were eligible. Exclusion criteria at the time of surgical intervention included (1) multiple congenital anomalies, (2) recognizable genetic or phenotypic syndrome at birth (other than chromosome 22q11 microdeletions), and (3) language other than English spoken in the home.

Five surgeons, with a dedicated team of cardiac anesthesiologists, performed the operations. Alpha-stat blood gas management was used. Deep hypothermic circulatory arrest (DHCA) was used at the discretion of the surgeon. Before DHCA, patients underwent core cooling with topical hypothermia to a nasopharyngeal tem- perature of $18^{\circ} \mathrm{C}$. Modified ultrafiltration was performed in all patients.

\section{Neurodevelopmental Examination}

The protocol for the neurodevelopmental examination has been previously described. ${ }^{6}$ Briefly, children were evaluated at 12 months of age \pm 2 weeks, adjusted for prematurity. Development was assessed by using the Bayley Scales of Infant Development II, which yields scores in 2 areas. The Psychomotor Development Index (PDI) assesses control of gross motor function, fine motor skills, use of writing instruments, and imitation of hand movements. The Mental Development Index (MDI) evaluates memory, problem solving, early number concepts, generalization, vocalizations, and language and social skills. Both the PDI and MDI yield a standard score. The mean is 100, with a standard deviation of 15 . Therefore a score of 70 or less is greater than 2 standard deviations below the mean. Evaluation also included a medical history, growth measurements, and detailed neurologic examination. The neurologic examination assessed active and passive tone, reflexes, gross motor skills, and visual and auditory responses. The results of the neurologic examination were classified as normal if no abnormalities or only mild abnormalities that did not affect motor skills were found, suspect when there was a moderate degree of abnormality, and abnormal when functionally significant abnormalities of tone, reflexes, or motor skills were present. Microcephaly was defined as a head circumference less than or equal to the 5th percentile for age. A genetic dysmorphologist evaluated the physical findings of every patient. Chromosome analysis and testing for microdeletions of chromosome $22 \mathrm{q} 11$ were performed as indicated. Results of the genetic evaluations were classified as normal, abnormal if a specific diagnosis was confirmed, or suspect if evidence of a genetic syndrome was present but confirmation was not possible. Because recognition of genetic syndromes in neonates can be difficult, some children with genetic abnormalities had been enrolled as infants. The genetic dysmorphologist was blinded to the findings of the developmental testing.

\section{Statistical Analysis}

Continuous data are expressed as means \pm standard deviation (range). Discrete data are expressed as proportions. Independent $t$ tests were used for comparison of continuous variables. Fisher exact and $\chi^{2}$ tests were used for comparison of discrete variables as appropriate. Linear regression was used to assess associations between risk factors and MDI and PDI outcomes. Potential predictors included gestational age, ethnicity, socioeconomic status as determined by parental reporting, birth weight, birth length, birth head circumference, Apgar score at 1 and 5 minutes, preoperative intubation and prostaglandin use, aortic arch obstruction, presence of a confirmed or suspected genetic syndrome, apolipoprotein E polymorphism, age and weight at surgical intervention, total support time (duration of cardiopulmonary bypass and DHCA), number of bypass runs, and use of DHCA. Ethnic classification was used as a single categoric variable with 5 levels in the univariate analysis and was divided into 5 binary variables for the multivariate analysis. Because the presence of a confirmed or suspected genetic syndrome was such a strong univariate predictor of developmental score, the cohort was divided on the basis of whether a genetic syndrome was detected. Separate multivariable analyses 
TABLE 1. Baseline characteristics and intraoperative statistics of the study group and the enrolled patients who did not return for neurodevelopmental testing

\begin{tabular}{|c|c|c|c|}
\hline & $\begin{array}{l}\text { Study group } \\
(\mathrm{n}=55)\end{array}$ & $\begin{array}{l}\text { Enrolled patients who did } \\
\text { not return }(\mathrm{n}=29)\end{array}$ & $P$ value \\
\hline \multicolumn{4}{|l|}{ Baseline characteristics } \\
\hline Gestational age, wk & $38.4 \pm 2.0$ & $38.7 \pm 2.7$ & .580 \\
\hline Birth weight, kg & $3.1 \pm 0.7$ & $3.0 \pm 0.7$ & .664 \\
\hline Head circumference, $\mathrm{cm}$ & $33.5 \pm 2.0$ & $33.2 \pm 2.5$ & .620 \\
\hline Microcephaly (head circumference $\leq 5 \%$ ), $n$ & $10(18 \%)$ & $6(21 \%)$ & .320 \\
\hline Preoperative intubation, $\mathrm{n}$ & $6(11 \%)$ & $6(21 \%)$ & .090 \\
\hline Preoperative prostaglandin, $\mathrm{n}$ & $15(27 \%)$ & $9(31 \%)$ & .301 \\
\hline Aortic arch obstruction, $\mathrm{n}$ & $19(35 \%)$ & $13(45 \%)$ & .356 \\
\hline \multicolumn{4}{|l|}{ Operative data } \\
\hline Age at operation, mo & $2.1 \pm 1.7$ & $2.2 \pm 2.0$ & .801 \\
\hline Weight at operation, $\mathrm{kg}$ & $4.1 \pm 1.2$ & $3.9 \pm 0.9$ & .334 \\
\hline Total support time, min & $73.0 \pm 40.9$ & $91.8 \pm 75.9$ & .143 \\
\hline Total cardiopulmonary bypass time, min & $53.4 \pm 26.5$ & $71.3 \pm 69.6$ & .192 \\
\hline Use of DHCA, $n$ & $28(51 \%)$ & $15(52 \%)$ & .943 \\
\hline Total DHCA time, min & $38.5 \pm 21.4$ & $39.6 \pm 24.8$ & .876 \\
\hline
\end{tabular}

DHCA, Deep hypothermic circulatory arrest.

were performed on each of these groups. Univariate predictors that were marginally significant at a $P$ value of less than .10 were then evaluated by using multivariable linear regression models.

\section{Results}

Between October 6, 1998, and March 24, 2003, 106 eligible patients underwent surgical intervention for a VSD or a VSD with aortic arch obstruction. A total of $85(80 \%)$ patients were enrolled. There was no hospital mortality. One (1.2\%) patient died after hospital discharge before 1 year of age. Of the 84 potential patients, $55(65 \%)$ returned for the 1 -year evaluation and constitute the study population.

The baseline characteristics and intraoperative statistics of the study group are detailed in Table 1 . In addition to the VSD, $19(35 \%)$ patients (coarctation of the aorta, $\mathrm{n}=14$; interrupted aortic arch, $\mathrm{n}=5$ ) in the study group also had aortic arch obstruction. Twenty-eight $(51 \%)$ patients in the study group received DHCA during their operations. Two patients in the study group had one additional operation requiring cardiopulmonary bypass. There was no statistically significant difference in baseline and intraoperative statistics between the study group and those enrolled patients who did not return for neurodevelopmental testing (Table 1). However, there was a trend toward longer total support time and total cardiopulmonary bypass time for the nonreturning patients.

At the time of neurodevelopmental testing, the mean age of the study group was 12.4 \pm 0.5 months (range, 11.6-13.9 months). The mean weight was $9.5 \pm 1.3 \mathrm{~kg}$ (range, 7.0$13.9 \mathrm{~kg}$; percentile for age, $40.4 \pm 29.4$ ), and the mean head circumference was $46.0 \pm 1.9 \mathrm{~cm}$ (range, $41.0-50.2 \mathrm{~cm}$; percentile for age, $46.2 \pm 32.8)$. Ten $(18 \%)$ patients had microcephaly at the time of testing. Of these 10 patients, 4 (40\%) had microcephaly at birth. At the time of testing, 19 (35\%) patients in the study group had a confirmed or suspected genetic syndrome. Six of these patients had a 22q11 microdeletion, 3 patients had undefined dysmorphic features, 1 patient was suspected of having tuberous sclerosis, and 9 patients were suspected of having a chromosomal abnormality (including, for example, 22q11 microdeletion and Turner's syndrome), with chromosomal and telomere analysis incomplete at the time of study termination. Of the 10 patients with microcephaly at the time of testing, $8(80 \%)$ had a confirmed or suspected genetic syndrome.

Six $(11 \%)$ patients had an abnormal neuromuscular examination, and $5(9 \%)$ had a suspect examination. Varying degrees of hypotonia accounted for all abnormalities on the neurologic examination. Of these 11 patients, $9(82 \%)$ had a confirmed or suspected genetic syndrome, and $5(45 \%)$ had microcephaly.

For the entire study group, the mean MDI score was $92.6 \pm 11.7$ (range, 56-117), with $3(5 \%)$ patients scoring 70 or less (Figure 1). The mean PDI score was $86.1 \pm 16.4$ (range, 50-121), with 10 (18\%) patients scoring 70 or less (Figure 1). The MDI and PDI scores were significantly lower in patients with a known or suspected genetic syndrome compared with scores in those without (MDI score: $86.2 \pm 14.5$ vs $96.1 \pm 8.1, P=.011$; PDI score: $76.6 \pm$ 18.3 vs $91.2 \pm 12.9, P=.001$; Figures 1 and 2 ).

The frequency of use $(95 \%$ vs $28 \%, P=<.001)$ and duration $(45.0 \pm 22.3$ vs $26.7 \pm 13.8$ minutes, $P=.027)$ of DHCA were greater in those patients with aortic arch obstruction compared with in those without. However, the MDI and 

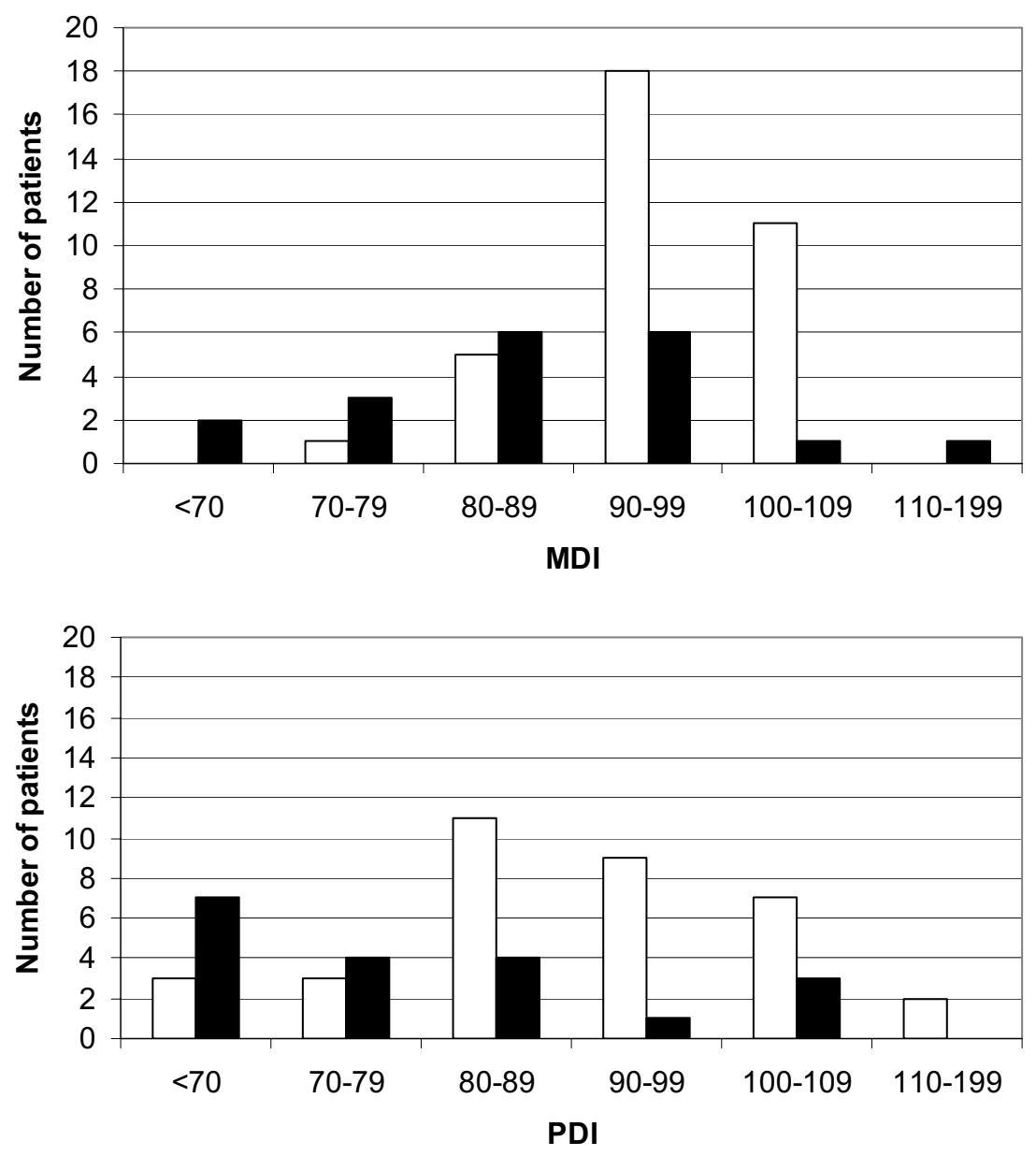

Figure 1. Range of Mental Development Index (MDI) and Psychomotor Development Index (PDI) scores of the Bayley Scales of Infant Development II for the patient cohort divided by results of the genetic evaluation.

$\square$ Normal genetic evaluation $\square$ Abnormal/suspect genetic evaluation

PDI scores were not significantly different between patients with arch obstruction and those without (MDI score: $93.4 \pm$ 6.3 [with] vs $92.2 \pm 13.9$ [without], $P=.680$; PDI score: $89.8 \pm 16.8$ [with] vs $84.1 \pm 16.1$ [without], $P=.226$ ) (Figure 3).

For the group of patients without a genetic syndrome, there was no significant multivariate predictor of MDI or PDI scores. For the group of patients with a suspected or confirmed genetic syndrome, as determined by means of multivariable analysis, there was no significant predictor of MDI score, and only lower birth weight predicted lower PDI score $(P=.025)$. No other patient-related factors, including socioeconomic status and apolipoprotein E genotype, or intraoperative factors, including cardiopulmonary bypass and circulatory arrest times, were significant predictors of neurodevelopmental outcome for either cohort.

\section{Discussion}

This study demonstrates that neurodevelopmental outcome at 1 year of age was within the normal limits for most patients who underwent repair of a VSD or a VSD with aortic arch obstruction during infancy. Patients with a known or suspected genetic syndrome had worse outcome than those without genetic abnormalities. In multivariate predictive models lower birth weight predicted lower PDI scores in those patients with a genetic syndrome. In addition, MDI and PDI scores were independent of anatomic (specifically aortic arch obstruction) and intraoperative (specifically use or duration of DHCA) factors. It should be noted that the study cohort as a whole and even those without a genetic syndrome scored slightly worse on the PDI score compared with the MDI score in relation to the population mean. However, the majority $(82 \%)$ of the cohort was within 2 standard deviations of the mean for a normal population.

Despite the more complex anatomy and surgical repair in patients with a VSD and coexisting arch obstruction, we could determine no difference in outcome at 1 year of age. This was a surprising finding because patients with coexisting arch obstruction have risk factors previously shown in other lesions to adversely affect neurodevelopmental out- 

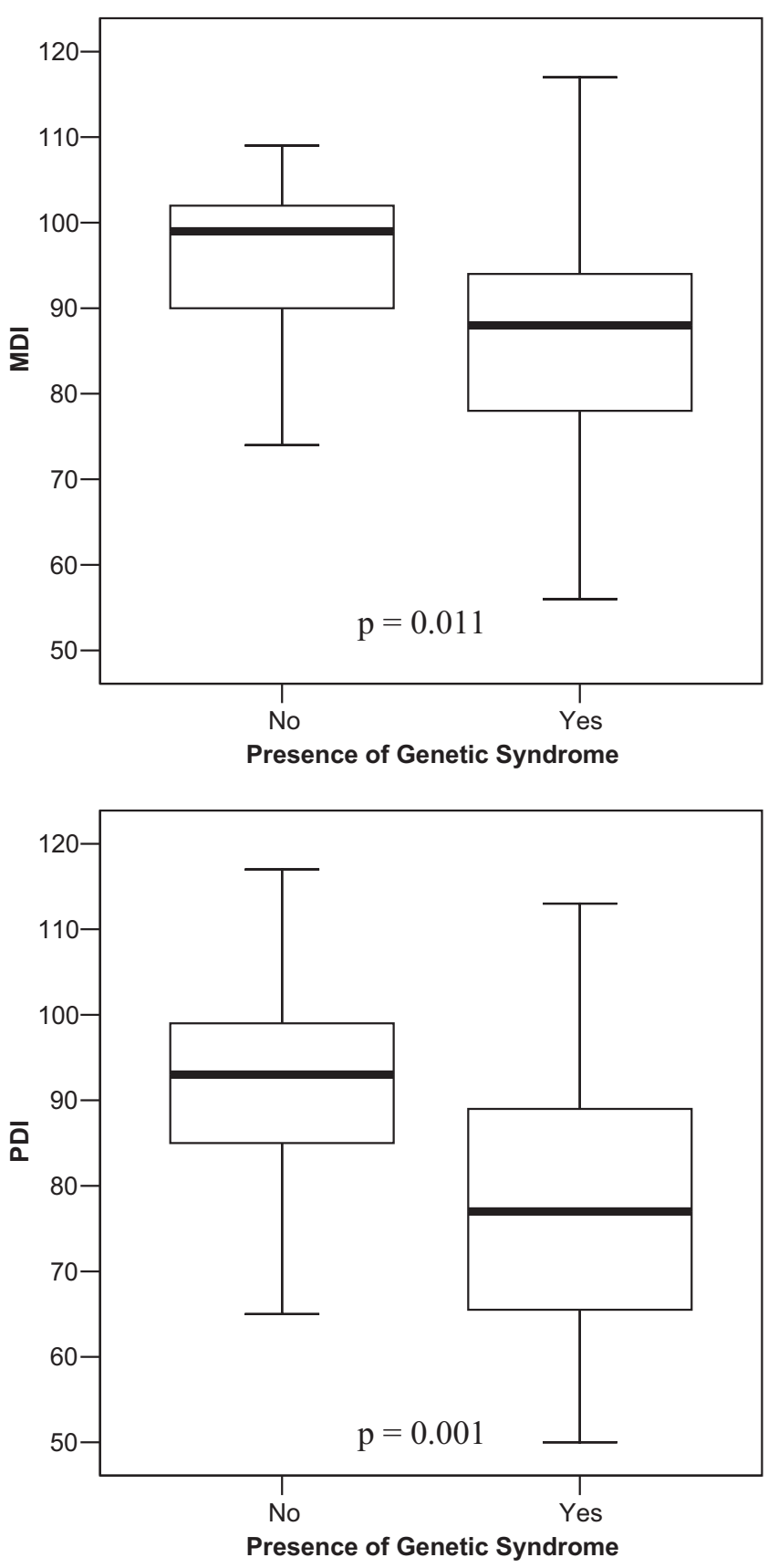

Figure 2. Mental Development Index (MDI) and Psychomotor Development Index (PDI) scores for patients with and without the presence of a confirmed or suspected genetic syndrome.

comes, including abnormal fetal cerebral vascular resistance, ${ }^{7}$ preoperative hemodynamic instability, exposure to cardiopulmonary bypass and DHCA in the neonatal period, ${ }^{8}$ and a longer postoperative stay in the intensive care unit. ${ }^{9}$ In addition, patients with a VSD and an interrupted aortic arch have a higher incidence of 22q11 deletion than those with isolated VSD. ${ }^{10}$ The findings of the current report support the strategy of early complete repair of VSD with arch obstruction. ${ }^{5,11-13}$ Previous studies have suggested that patients undergoing the 2-stage approach have lower mortality. ${ }^{11}$ However, our group and others have recently shown excellent operative results after single-stage repair. ${ }^{5,13}$ An important consideration of the single-stage approach is that the patient might be exposed to DHCA in the neonatal period, with potentially deleterious effects on neurocognitive development. This study demonstrates that despite being exposed more frequently to DHCA and to longer durations of DHCA, the patients undergoing aortic arch repair and VSD closure had 1-year neurodevelopmental outcomes similar to those of patients who underwent VSD closure alone as infants.

With the improved success of surgical intervention in patients with congenital heart disease, the research focus has shifted to understanding long-term morbidity, including neurodevelopmental outcome. Many of these studies have focused on outcome after surgical intervention for complex congenital heart disease, such as d-transposition of the great arteries (d-TGA) 2,14,15 and hypoplastic left heart syndrome. ${ }^{3}$ Others have followed cohorts of patients in which various anatomic subtypes of heart disease have been grouped together. ${ }^{4,16,17}$ Little is specifically known about neurodevelopmental outcome after surgical intervention for a VSD, despite the fact that VSDs are the most common congenital heart defect and one of the most common indications for surgical intervention.

Two studies have described neurodevelopmental outcome after surgical intervention for a VSD, although not as the primary goal of the study. Hesz and Clark ${ }^{18}$ compared the cognitive development of children after the atrial switch operation for d-TGA with that of children who had undergone VSD repair $(\mathrm{n}=8)$ and with that of healthy siblings. They showed that the children with VSDs scored higher on academic achievement and intelligence tests than those with d-TGA. The authors speculated that the cause of the developmental delay in the patients with TGA is related to decreased cardiac reserve, chronic hypoxemia, and parental restrictions on their debilitated child's activities. Bellinger and colleagues ${ }^{19}$ compared preschool developmental outcome after randomization with different $\mathrm{pH}$ management strategies during deep hypothermic cardiopulmonary bypass surgery for congenital heart disease in infancy. The authors reported a significantly worse MDI outcome for the subgroup of patients with a VSD (and common atrioventricular canal, $\mathrm{n}=16$ ) compared with that in patients with d-TGA. Patients with specific congenital anomalies and known genetic syndromes were excluded; however, formal genetic evaluation was not performed. The discrepancy in outcome was speculated to result from the chance occurrence of 22q11 microdeletion in the VSD subgroup. Both of these 

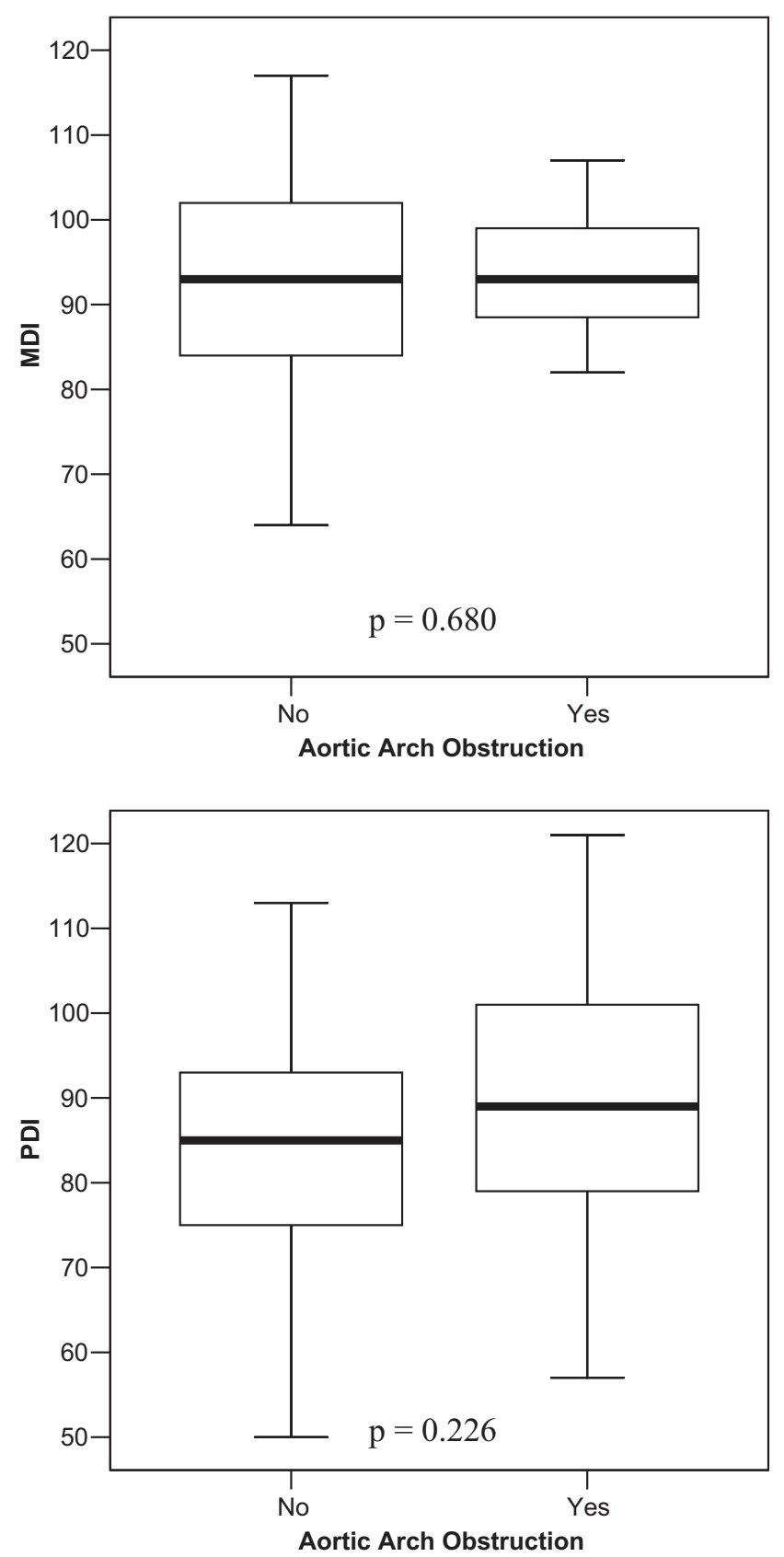

Figure 3. Mental Development Index (MDI) and Psychomotor Development Index (PDI) scores for patients with and without aortic arch obstruction.

studies were limited by small sample size in the VSD subgroup.

Even after exclusion of children who had identifiable genetic syndromes at the time of surgical intervention, the most important predictor of neurodevelopmental outcome in this study was the presence of a confirmed or suspected genetic syndrome at 1 year of age. The most common confirmed genetic syndrome in the study cohort was chromosome 22q11 microdeletion syndrome. Gerdes and coworkers ${ }^{20}$ demonstrated a range of developmental disabilities in children with the 22q11 deletion, with notable delays in speech and language development. The authors also showed that these disabilities were not explained by cardiac disease or cardiac surgery. In this subset of patients with a confirmed or suspected genetic syndrome, lower birth weight was an additional and independent predictor for lower PDI scores. Although the presence of 22q11 microdeletion syndrome and low birth weight are associated, ${ }^{21}$ lower birth weight and decreased gestational age are recognized predictors of poor developmental outcome in otherwise healthy children. ${ }^{22}$

Interestingly, MDI and PDI scores at 1 year were independent of intraoperative factors, such as cardiopulmonary bypass and circulatory arrest time. Intraoperative variables have been extensively investigated for their effect on neurodevelopmental outcome. ${ }^{4,14,15,23}$ Duration of DHCA has been shown to have a negative effect on IQ and developmental testing scores. The effect of DHCA is most likely nonlinear, and neurodevelopmental disability is unlikely with shorter periods of DHCA $\left(<41\right.$ minutes). ${ }^{23}$ In our study the mean duration of DHCA was 38.5 minutes, and duration of DHCA was not a significant predictor of neurodevelopmental outcome. However, these results should be interpreted cautiously because this study was not primarily powered to evaluate the effects of DHCA duration on neurodevelopment.

In a large prospective trial assessing the effects of genetic polymorphisms on neurodevelopmental disabilities after infant cardiac surgery, which included the patients in this study, the apolipoprotein E $\epsilon 2$ allele was found to be predictive of lower PDI scores at 1 year of age. ${ }^{6}$ In the VSD cohort apolipoprotein E polymorphism was not predictive of neurodevelopmental outcome. This might also be related to insufficient sample size to address this issue.

\section{Limitations}

The results of this study should be evaluated in the context of certain limitations. There is the possibility of selection bias in the study because $35 \%$ of the enrolled patients did not return for developmental testing. The most common reason for not returning was lack of funds. This might indicate a potential selection bias with regard to socioeconomic status. Furthermore, although comparison of baseline and intraoperative variables suggested that there was no significant difference between those who did not return and the study group, there was a possible trend toward longer total support time and total cardiopulmonary bypass time for the nonreturning patients. Given the large variability, these differences did not reach statistical significance. Second, this study was a post-hoc analysis of a subset of 
patients from a larger study population and was therefore not specifically powered to evaluate predictors of neurodevelopmental outcome in patients with a VSD. Finally, neurodevelopmental outcome at 1 year is minimally predictive of outcome in later life. ${ }^{24}$ Therefore only re-evaluations at older ages can determine long-term neurodevelopmental outcome of this patient population. Extensive neurodevelopmental re-evaluation of this cohort is currently being performed as the patients reach 4 years of age.

\section{Conclusions}

In summary, most patients who underwent repair of a VSD with or without aortic arch obstruction in infancy had normal neurodevelopment at 1 year of age. The presence of a confirmed or suspected genetic syndrome predicted worse outcome. Patients with these characteristics therefore should be targeted for early intervention and support after surgical repair. In addition, patients who undergo single-stage repair of a VSD and aortic arch obstruction have similar neurodevelopmental outcome to patients undergoing VSD repair alone. On the basis of our previous work, which demonstrated acceptable mortality after single-stage repair, ${ }^{5}$ and the results of the current study, which suggest minimal neurodevelopmental morbidity, we would recommend the single-stage approach for moderate to large-sized VSDs and aortic arch obstruction.

\section{References}

1. Bol-Raap G, Weerheim J, Kappetein AP, Witsenburg M, Bogers AJ. Follow-up after surgical closure of congenital ventricular septal defect. Eur J Cardiothorac Surg. 2003;24:511-5.

2. Bellinger DC, Jonas RA, Rappaport LA, Wypij D, Wernovsky G, Kuban KC, et al. Developmental and neurologic status of children after heart surgery with hypothermic circulatory arrest or low-flow cardiopulmonary bypass. N Engl J Med. 1995;332:549-55.

3. Mahle WT, Clancy RR, Moss EM, Gerdes M, Jobes DR, Wernovsky G. Neurodevelopmental outcome and lifestyle assessment in schoolaged and adolescent children with hypoplastic left heart syndrome. Pediatrics. 2000;105:1082-9.

4. Limperopoulos C, Majnemer A, Shevell MI, Rosenblatt B, Rohlicek C, Tchervenkov C, et al. Functional limitations in young children with congenital heart defects after cardiac surgery. Pediatrics. 2001;108:1325-31.

5. Gaynor JW, Wernovsky G, Rychik J, Rome JJ, DeCampli WM, Spray TL. Outcome following single-stage repair of coarctation with ventricular septal defect. Eur J Cardiothorac Surg. 2000;18:62-7.

6. Gaynor JW, Gerdes M, Zackai EH, Bernbaum J, Wernovsky G, Clancy $\mathrm{RR}$, et al. Apolipoprotein E genotype and neurodevelopmental sequelae of infant cardiac surgery. J Thorac Cardiovasc Surg. 2003;126:1736-45.
7. Kaltman JR, Di H, Tian Z, Rychik J. Impact of congenital heart disease on cerebrovascular blood flow dynamics in the fetus. Ultrasound Obstet Gynecol. 2005;25:32-6.

8. Galli KK, Zimmerman RA, Jarvik GP, Wernovsky G, Kuypers MK, Clancy R, et al. Periventricular leukomalacia is common after neonatal cardiac surgery. J Thorac Cardiovasc Surg. 2004;127:692-704.

9. Newburger JW, Wypij D, Bellinger DC, du Plessis AJ, Kuban KC, Rappaport LA, et al. Length of stay after infant heart surgery is related to cognitive outcome at age 8 years. J Pediatr. 2003;143:67-73.

10. Goldmuntz E, Clark BJ, Mitchell LE. Frequency of 22q11 deletions in patients with conotruncal defects. J Am Coll Cardiol. 1998;32:492-8.

11. Quaegebeur JM, Jonas RM, Weinberg AD, Blackstone EH, Kirklin JW. Outcomes in seriously ill neonates with coarctation of the aorta: a multiinstitutional study. J Thorac Cardiovasc Surg. 1994;108:841-54.

12. Isomatsu Y, Imai Y, Shin'oka T, Aoki M, Sato K. Coarctation of the aorta and ventricular septal defect: should we perform a single-stage repair? J Thorac Cardiovasc Surg. 2001;122:524-8.

13. Kostelka M, Walther T, Geerdts I, Rastan A, Jacobs S, Dahnert I, et al. Primary repair for aortic arch obstruction associated with ventricular septal defect. Ann Thorac Surg. 2004;78:1989-93.

14. Bellinger DC, Wypij D, Kuban KC, Rappaport LA, Hickey PR, Wernovsky G, et al. Developmental and neurological status of children at 4 years of age after heart surgery with hypothermic circulatory arrest or low-flow cardiopulmonary bypass. Circulation. 1999;100:526-32.

15. Bellinger DC, Wypij D, du Plessis AJ, Rappaport LA, Jonas RA, Wernovsky G, et al. Neurodevelopmental status at eight years in children with dextro-transposition of the great arteries: the Boston circulatory arrest trial. J Thorac Cardiovasc Surg. 2003;126:1385-96.

16. Forbess JM, Visconti KJ, Hancock-Friesen C, Howe RC, Bellinger DC, Jonas RA. Neurodevelopmental outcome after congenital heart surgery: results from an institutional registry. Circulation. 2002 106(suppl):I95-102.

17. Dittrich H, Buhrer C, Grimmer I, Dittrich S, Abdul-Khaliq H, Lange PE. Neurodevelopment at 1 year of age in infants with congenital heart disease. Heart. 2003;89:436-41.

18. Hesz N, Clark EB. Cognitive development in transposition of the great vessels. Arch Dis Child. 1998;63:198-200.

19. Bellinger DC, Wypij D, du Plessis AJ, Rappaport LA, Riviello J, Jonas RA, et al. Developmental and neurologic effects of alpha-stat versus $\mathrm{pH}$-stat strategies for deep hypothermic cardiopulmonary bypass in infants. J Thorac Cardiovasc Surg. 2001;121:374-83.

20. Gerdes M, Solot C, Wang PP, Moss E, LaRossa D, Randall P, et al. Cognitive and behavior profile of preschool children with chromosome 22q11.2 deletion. Am J Med Genet. 1999;85:127-33.

21. Brauner R, de Gonneville ALH, Kindermans C, Le Bidois J, Prieur M, Lyonnet $\mathrm{S}$, et al. Parathyroid function and growth in 22q11.2 deletion syndrome. J Pediatr. 2003;142:504-8.

22. Pietz J, Peter J, Graf R, Rauterberg-Ruland I, Rupp A, Sontheimer D, et al. Physical growth and neurodevelopmental outcome of nonhandicapped low-risk children born preterm. Early Hum Dev. 2004;79:131-43.

23. Wypij D, Newburger JW, Rappaport LA, duPlessis AJ, Jonas RA, Wernovsky G, et al. The effect of duration of deep hypothermic circulatory arrest in infant heart surgery on late neurodevelopment: the Boston circulatory arrest trial. J Thorac Cardiovasc Surg. 2003;126:1397-403.

24. McGrath E, Wypij D, Rappaport LA, Newburger JW, Bellinger DC. Prediction of IQ and achievement at age 8 years from neurodevelopmental status at age 1 year in children with D-transposition of the great arteries. Pediatrics. 2004;114:572-6. 